It is ea to theorise, and to say it is a reflex action due to stretching of the uterine walls, but no one has got beyond the conception of the hypothesis. But, supposing for a moment that this is the correct interpretation of the ordinary vomiting of pregnancy, we are still a long way off the solution of the question what causes the severe vomiting in pregnancy. For, first of all, we must assume that the vomiting is due to the pregnancy, and not to some other unrecognised condition ; in other words, that it is severe vomiting of pregnancy; and then we have got to show what particular part of the reflex loop is at fault. We see the motor end, that is, the vomiting apparatus, in excessive and dangerous action; and the question is, why does this occur.

One might resolve the numerous theories that could be brought forward into three kinds. 1. "Alteration in the stimuli ;" by which is meant increase in degree or kind of that condition of the uterus, stretching of its fibres, or whatever it is, which causes the ordinary vomiting of pregnancy; and this increase may be brought about in numerous ways, including malpositions of the uterus. 2. "Increased irritability of the afferent nerves or reflex centres, or efferent nerves, which form the reflex loop between the uterus and the muscles engaged in vomiting." If it could be shown by microscopic examinations that, in these cases of severe vomiting, the spinal grey matter between the entrance of the afferont (uterine?) nerves, and the exit of the efferent nerves for vomiting (gastric, csophageal, phrenic, pneumogastric, intercostal, etc.) was in a state of increased irritability, either from disease in itself or in neighbouring parts, it would not only help to explain these cases, but would in itself support the reflex hypothesis of the ordinary vomiting of pregnancy. But, so far as I know, no observations have been made in reference to the condition of the spinal cord in the severe cases of vomiting; so that we do not know, either negatively or positively, the condition of the so-called superficial and deep reflexes during life, nor of the normal or abnormal histological appearances of the spinal cord after death. 3. "Increased irritability of the muscles themselves, which produce vomiting." I have often heard Dr. Wilks say that excessive action of an organ is not generally due to disease of that organ; for instance, severe palpitation is not due to heart-disease, and severe vomiting is generally performed by a healthy stomach. Hence one does not expect to find a diseased stomach in these cases. At the same time, the muscular fibres in the stomach, without being diseased, might be more irritable from some cause or other, such as irritable ingredients in the blood, or pathological conditions of neighbouring parts-for example, hepatic disease.

All these theories on theories require supporting by many facts and observations, before they can be accepted as satisfactory.

Dr. Graily Hewitt has brought forward several facts in support of his view that malposition of the uterus is a cause of severe vomiting in pregnancy; but many cases are on record, amongst which I would place my own, in which no malposition existed. Hence it follows that the severe vomiting in pregnancy may be due to different causes.

In women, vomiting is set going more easily than in men; and any cause which would produce sickness in a non-pregnant state would act more potentially, if anything, if pregnancy existed. Hence the possible causes of severe vomiting in pregnancy are as varied as the causes of severe vomiting in a non-presnant state.

Of the causes of severe vomiting of pregnaney we know very little at present ; but one thing seems to me quite clear, and that is, that the excessive sickness is not always due to the same cause; and, even if it be accepted that malpositions of the uterus will sometimes produce the symptom, it will be found that cases occur where this cannot be the explanation.

\section{THE PREVENTION OF CONSUMPTION.}

\section{By G. ROSS FRASER, L.R.C.P.Ed., Wark-on-Tyne.}

IN the course of Dr. Hawksley's remarks, in the Joursal of June 6th, upon Parasiticides in the Treatment of Pulmonary Consumption, he raises the question whether the immunity alluded to is to be ascribed "simply to atmospheric exposure, or to the physiological or parasiticide action of the chemical products of certain burning bodies.' According to Dr. Morgan, the non-prevalence of consumption among the crofter population of the Hebrides and north-western coast of Scotland is due to the antiseptic properties of peat-smoke, which, from the construction of their dwellings and the nature of the fuel used, they largely inhale. That consumption is eminently preventable, is evident from the fact that, in one set of circumstances, the population in question, to a large extent at any rate, escape this scourge, while in another they become victims.
If Dr. Morgan's clearly propounded views be correct, then we may in time be furnished with additional resources in deaing with the causes that lead to the phthisical state. But, surely, the happy immunity enjoyed by these people can, with good reason, be credited to other causes than to the real or supposed prophylactic virtues of peat or any other kind of smoke.

I have seen much of crofter life in the far north of Scotland, and can safely say that few other classes live under conditions so favourable to health and longevity. Their easy out-door life, plain but nutritious diet, by no means deficient in variety, warm homespun clothing, and the equable temperature, and the fairly good internal cubic space of their homely dwellings, go very far to account for their physical vigour and immunity from tubercular disease. Chimnied dwellings are gradually displacing those ancient dark domiciles in Sutherlandshire. These were low, but long in form. The fire was placed against a slightly raised piece of mason-work near the middle of the main apartment, the smoke finding exit through a barrel, minus top and bottom, fixed in an opening in the roof. The side-walls, from six to eight feet high, supported a roof whose ridge rose 10 or 12 feet above them, and, as no ceiling existed, the cubic space internally was generally large. From long exposure to peatsmoke, the bare rafters overhead acquired a black unctuous-looking coating, as if newly coal-tarred. This deposit had a powerful peaty odour, and every object within the hut was similarly affected. The aërial fumigation was complete, and yet consumption, although rare, was by no means altogether unknown. To a casual observer, these sable abodes might seem to reek with impurities. In reality, it was not so; for, while frequently under one roof, and in a sense with a common entrance, a strong walled partition with a door separated the bovine from the human inmates. The byre had openings in the walls and roof, and its door generally stood open, a large supply of fresh ain being always necessary where cattle are "housed," on account of their size and normally high temperature $\left(102^{\circ}\right)$.

I have now before me a volume entitled $D r$. Beddoes on Consumption (London, 1801). A part of the book is devoted to considerations on a modified atmosphere in consumptive cases. This modified atmosphere is no other than that of a well stocked byre. Patients of means grudged no expense in fitting up cow-houses, where they took up their quarters for lengthened periods; and, as usual in new methods of treatment in consumption, case after case is cited to prove its undoubted efficacy.

In support of his theory, Dr. Morgan remarks that, "when these Highlanders migrated to other parts of the country, or took up their abodes in chimnied dwellings, they suffered like their neighbours." This observation is at least equally true of many Highlanders, whether they be of the crofter class or not. The migration necessarily entails changes in their mode of living, not always of a healthful kind. Highlanders, as clerks or as university students, frequently suffer. It must always be so when young men accustomed to country life engage too abruptly in prolonged and sedentary work.

The term "chimnied dwellings" suggests an inquiry of the highest practical value. In reality, the assumed hygicnic superiority of many of our chimnied dwellings is, to say the least, doubtful. In the great majority of them, direct communication with the external air by means of open chimney-flues (as far as bedrooms are concerned) is the exception and not the rule. I speak from observation. There is a widely prevalent custom of cramming bedroom-flues with sacks filled with hay or straw, for the purpose of excluding cold in winter, and in all seasons for protecting the grate and furnishings from the tarnishing effects of descending rains. If the establishment boast of a spare bedroom, the largest and best furnished is chosen for the purpose, while the remaining rooms are often tos small and overcrowded, and frequently possessed of no flues to close. Is it surprising that families bred in this manner are seldom all well together? The evil is, no doubt, to a certain extent neutralised by the active outdoor habits of the young people during the day; but who can doubt that many of them, partly from this cause, grow up a "feeble folk," with a predisposition to pulmonary disease? Until the homes of the people, their schools, their workshops, offices, and warehouses, are constructed with more regard than generally prevails to sanitary requirements, no marked advance in the prevention of this disease can be looked for. The loss of many valuable lives by consumption is all the more painful from the certainty that, to a great extent, it might have been avoided. In the absence of pure air, physical exercise, sufficient food and clothing, antiseptics can be of little avail against the inroads of the bacillus. They are useful so far as they destroy atmospheric impurities. Their extended use in medicine and surgery has served a good purpose, by directing more general attention to the advantages of cleanliness and ventilation; but we cannot hope by their most 
potent and skilful application alone to ward off the effects of persistent transgression of the terms, upon which it is possible for us to maintain our organism in that degree of health of which it is capable.

\section{SURGICAL MEMORANDA.}

CASE OF RECOVERY FROM MALIGNANT PUSTULE.

Mr. F., aged 31 , a veterinary surgeon, experienced on October 6 th a stinging sensation at the back of the right wrist. A small bleb was formed, which he scratched off, and there was some tenderness of the elbow and arm-pit. He had a slight rigor. On October 8 th, he was seen by Dr. Meadows, who prescribed some salicylate of soda and tincture of aconite, in frequent doses, as his temperature was $104^{\circ}$, and the rigors continued almost the whole of the day. A black eschar began to form on the afternoon of the 8th, and on the 9th it became about the size of a sixpence ; its base was red and œdematous, and surrounded by some vesicles in a circular shape.

The temperature was nearly $104^{\circ}$; the patient felt cold, and his tongue was foul. I visited the case with Dr. Meadows, and we injected pure carbolic acid under the eschar, using an ordinary hypodermic syringe. Unfortunately, we could only introduce a small quantity, as it oozed out in the withdrawal of the syringe, and with it a serouslooking fluid. I dried some of this fluid on a cover-glass, stained it with methyl-violet, and found the well-known bacilli of anthrax. We prescribed large and frequent doses of soda-hyposulphite, and ordered also a large quantity of meat. Under this treatment, he rapidly improved.

On October 12th, we again injected carbolic acid. The temperature came down, and, as the patient said he felt all right, the hyposulphite of soda was reduced to three times a day. The eschar did not finally separate for nearly six weeks, and the ulcer then soon healed. I believe that the main remedy in this case was the injection of pure carbolic acid, a mode of treatment which does not seem rery painful.

There was a clear history of the disease, which was contracted exactly twelve days before its first appearance, Mr. F. having examined the flesh of an animal that had died from anthrax.

W. E. Buck, M.D.Cantab., Physician to Leicester Infirmary.

DIGITAL TENOTOMY IN PIANISTS.

THE operation referred to in the Journal of May 30th, as practised by Dr. Forbes, of Philadelphia, promises to be one of great benefit to accomplished pianists, as well as to learners. In making some dissections on the dead body, with a view to determine the usual position of the slips of tendon which limit the action of the extensor of the ringfinger, I found that these vary very much in different cases; so that it becomes necessary to carefully determine their position by the eye and finger, during movement of the extensor-tendon, in each case before operation. I have just succeeded in freeing the ring-finger of the right hand of an accomplished lady pianist, without causing her much more pain than is felt from the prick of a needle. Before operation, she was able to raise the finger only five-eighths of an inch beyond the others. Directly after operation, she could raise the finger easily to one-and-a-half inches, without the least feeling of loss of control over its action. The division was, of course, made subcutaneously, so that only a minute wound was left in the skin, one-eighth of an inch in length. Noble Smith, Queen Anne Street, W.

\section{THERAPEUTIC MEMORANDA.}

\section{QUININE IN THE TREATMENT OF PNEUMONIA.}

IN the Journal of June 20th, Dr. Suckling draws attention to the value of sulphate of quinine in the treatment of pneumonia, but states that he does not use it for children. My object is to prove that it is of as much use in the treatment of children as I have found, and he has shown, it to be in that of adults.

M. E., a girl, aged 5, was taken ill on April 28th. I was sent for on the 29 th, and found crepitations everywhere except at the apices ; temperature, $103^{\circ}$; pulse uncountable; respirations 40 and 45 . I treated this case by blistering and the usual remedies; but, though the temperature fell to $101^{\circ}$, the pulse remained uncountable, and the respirations rose to 60 and 64 . On the third day, the temperature being $104.5^{\circ}$, and the respirations 72 , I gave a grain of the sulphate of quinine, with five grains of salicylate of soda every two hours. After three doses, the temperature was $99^{\circ}$, the respirations 45 . Salicylate of soda I had been using before; I therefore attributed the fall in temperature to the quinine, and continued its use in three-quarter grain doses until convalescence.

W. S., a boy, aged 5, seen first on June 19th, had been ill four days. I found immense crepitation over the mammary and scapular regions of the right lung; temperature $104.5^{\circ}$; pulse 150 ; respirations 39 . I put on a large blister over the affected region anteriorly, and gave five grains of salicylate of soda, with three-fourths of a grain of sulphate of quinine every two hours. After two doses, the temperature was $99.2^{\circ}$; the following morning it was normal, and has never risen since.

These two cases show that the sulphate of quinine may he used with advantage in pneumonia in all stages, though certainly the best result may be expected from the early administration of the drug. Combination with salicylate of soda lessens that tendency to sickness often produced by quinine, and does not in the least interfere with its action. I never have found it necessary to give adults larger than three-grain doses of quinine under similar circumstances, and, after three doses, have generally reduced the temperature to normal. In all cases of inflammation within the chest, I never fail to blister with cantharides as early and as freely as possible, with the best results. James A. MYrTLe, M.B., C.M., Harrogate.

\section{HYDROCHLORATE OF CUCAINE IN HAY-FEVER.}

THE eye does not seem to be protected against the irritating action of the pollen-grain by two or three drops of a 2 per cent. solution of hydrochlorate of cucaine, though the inflammation and itching, arising from the swelling and bursting of the grain, are allayed and removed by its use.

I am trying stronger solutions. The violent sneezing and swelling of the mucous membrane of the nose, arising from the same cause, are removed by a few drops of a 1 per cent. solution, sniffed off a camel'shair brush; so that, up to the present, I have been comparatively free from nose-symptoms.

Probably, the only way to ascertain the exact prophylactic effect, if any, of the cucaine, is to procure pollen which lias a known irritating effect on the experimenter's conjunctiva, and to try its action on both eyes, having previously inserted solutions of varying strength into one of them; and these experiments I hope to carry out.

Apparently, as was anticipated, cucaine is at present our best topical application in the treatment of this distressing complaint, though I found vaseline of great service last hay-season for the nose. It certainly alleviates, and may be found prophylactic. The only other effect on the eye is a slight smarting, soon wearing off, and a little dilatation of the pupil, lasting about twelve hours. I hope that some other members may contribute their sersonal experience of its use in hay-fever.

J. Weston BulL, M.D., West Chislehurst, S.E.

\section{TOXICOLOGICAL MEMORANDA.}

\section{FATAL POISONING BY WHITE PRECIPITATE.}

PoIsoning by white precipitate (ammonio-chloride of mercury) being comparatively rare, I forward the following brief notes of a case recently under my care. The pationt was a baker, aged 52 , formerly of intemperate habits. For several months, until June 5th, he had been a total abstainer. On that day, I delivered his wife of a still-born child. During his wife's confinement to bed, he resumed his old habits, consuming large quantities of gin daily, and keeping himself more or less constantly under the influence of liquor. At 7.30 on Sunday morning, June 21st, I was called to see him, and found him in bed in great pain, vomiting blood freely, with cold clammy perspiration; soft, feeble, but rapid pulse; bloody stools ; and anxious expression. On search being made, a wine-glass was found containing a few grains of white powder, and a paper labelled "precipitate-powder-poison." $\mathrm{He}$ stated that he had also taken "some acid he had for his battery," which I found to be sulphuric acid; but he had taken only a few drops of the latter in water, and there were no signs of acid about the lips or mouth.

The treatment consisted in frequent doses of white of egg, which was generally quickly vomited, and doses of fire minims of tinctura opii with ten minims of tinctura hamamelis, every quarter of an hour, which appeared to allay both the pain and vomiting. However, he never rallied, and died at 12.20 , about five hours after taking the poison. None of the specific effects of mercury were present, the symptoms being purely those of irritant poisoning. On inquiry at the druggist's, I ascertained that the packet contained forty grains of white 